\title{
Quantifying Range of Motion and Stress Patterns at the Transitional Lumbosacral Junction: Pilot Study Using a Computational Model for Load-Bearing at Accessory L5-S1 Articulation
}

\author{
NILADRI KUMAR MAHATO, MBBS, MS, DNB, PHD, ${ }^{1,2}$ RAJA DHASON, ME, ${ }^{3}$ DV RAGHU RAM, M.TECH ${ }^{3}$ \\ ${ }^{1}$ Department of Preclinical Sciences, Faculty of Medical Sciences, The University of The West Indies, St. Augustine, Trinidad and Tobago, ${ }^{2}$ Ohio Musculoskeletal \\ \& Neurological Institute (OMNI), Department of Biomedical Sciences, Ohio University, Athens, Ohio, ${ }^{3}$ School of Mechanical Engineering, SRM Institute of \\ Science and Technology, Kancheepuram District, Tamil Nadu, India
}

\begin{abstract}
Background: Symptomatic or asymptomatic transitional anomalies at the lumbosacral junction are common occurrences in the population. Lumbosacral (L5-S1) accessory articulations are the most common presentations of transitional anomalies at this region. Such anatomical alterations are believed to be associated with biomechanical changes of load-bearing and movement restrictions leading to low back pain. This study attempts to use computational models of a normal and a lumbosacral transitional vertebrae (LSTV) accessory articulation to analyze and compare the range of motion and loading patterns at the lumbosacral articulations.

Methods: Three-dimensional Finite Element computational models of normal and accessory L5-S1 articulated sacrum were created. These models were tested for range of motion and stress patterns generated at the lumbosacral articulations using similar loading and motion simulation to elicit different moments/excursions at the lumbosacral junctions.

Results: Compared to the normal variant, the transitional model exhibited different range of motion and divergent patterns of stress generation at the lumbosacral and accessory articulations with equal and physiological magnitudes of loading applied to both the models.

Conclusions: The finite element modeling approach can be used for biomechanical investigations in LSTV variants. However, larger sample studies with different LSTV models may be required to statistically compare movement and loading patterns at LSTV-affected lumbosacral and sacroiliac junctions, and to recommend definitive treatment strategies in these situations.
\end{abstract}

Lumbar Spine

Keywords: accessory-articulation, Finite Element, low back pain, LSTV, pars inter-articularis, stress

\section{INTRODUCTION}

Lumbosacral transitional vertebrae (LSTV) are commonly found, with or without symptoms, in approximately $15 \%$ of all adults. ${ }^{1-4}$ L5-S1 transitions may present as (a) unilateral or bilateral accessory articulation between the extended L5 transverse process(es) and the sacral ala; (b) complete unilateral or bilateral fusion (sacralization) of the L5 with the first sacral segment (S1); or (c) unilateral or bilateral separation (lumbarization) of the S1 from the sacral mass. ${ }^{2,5}$ Transitional L5-S1 junctions demonstrate several anatomical alterations compared to the normal variants. ${ }^{6,7}$ These changes include alterations L5-S1 disc space heights, and dimensional and orientation changes of the facet joint and the sacral auricular surface areas, changes that are often linked with low back pain (LBP) ${ }^{8,9}$ Of all transitions, L5-S1 accessory articulations have been identified as the most common variety of LSTV. ${ }^{4,10}$

The lumbosacral junction allows different ranges of movement in all the three spatial planes. These movements include different degrees of flexionextension, lateral bending, and axial rotations. ${ }^{11-13}$ In normal circumstances, the L5-S1 articulations, namely the intervertebral disc and the facet joints are constantly subjected to multidirectional compressive and shear stress during day-to-day activities. ${ }^{14-18}$ Although the orientation of the lumbar facet articulation limits its rotation, facet joints form the posterior neural arch elements and are highly mechanically loaded structures. ${ }^{19}$ Since the 
lumbar spine presents a lordosis in the sagittal plane, the L5-S1 junction is subjected to accentuated forward shearing stress at the facet joints and the pars interarticularis. ${ }^{20-23}$ L5-S1 accessory articulated junctions are additionally associated with altered facet morphology, and may present with pain and restriction of movement. ${ }^{24-26}$ The sources of such pain have been identified at the L5-S1 or adjacent intervertebral discs, the facet joints, the anomalous accessory articulation, or a nerve root trapped between an extended L5 transverse process and the ala of the sacrum. ${ }^{27-31}$

Biomechanical evaluation of lumbosacral motion and stress patterns have been performed in active young volunteers, with cadaveric material and with computational vertebral models. ${ }^{32}$ However, analyses of load bearing patterns in LSTV junctions (including accessory articulations) using computational models have very rarely been reported. Since L5-S1 accessory articulations are the most prevalent form of LSTV in the population, this pilot study was attempted to (1) create an aberrant LSTV model of the sacrum previously unreported in the literature, (2) test the range of motion (ROM) permissible at the transitional junction with the specified magnitude of loading, (3) record the pattern of stress generated at all the L5-S1 articulations (including vertebral bodies, facets, L5 pars interarticularis and the anomalous accessory articulation), and (4) compare all the outcomes with similar motion and loading parameters applied to a normal sacral model. Abnormal loading patterns generated at these anatomical sites, specifically at the posterior vertebral elements, have been implicated in lumbosacral instability. ${ }^{21,33-35}$

\section{MATERIAL AND METHODS}

Three-dimensional finite element models of a normal and a lumbosacral junction with accessory L5-S1 articulation (left sided) between the extended transverse process and the left sacral ala was created using three-dimensional geometric models using CATIA software. The model was created from serial computed tomography scan images obtained from osteological samples of a normal sacrum, and a sacrum with corresponding L5 vertebra bearing the left-sided accessory articulation (Figure 1). All model dimensions were validated by measurements from dried human fifth lumbar vertebra and the sacrum. The motion-segment models included the vertebra, the sacrum, the end-plates, and the intervening

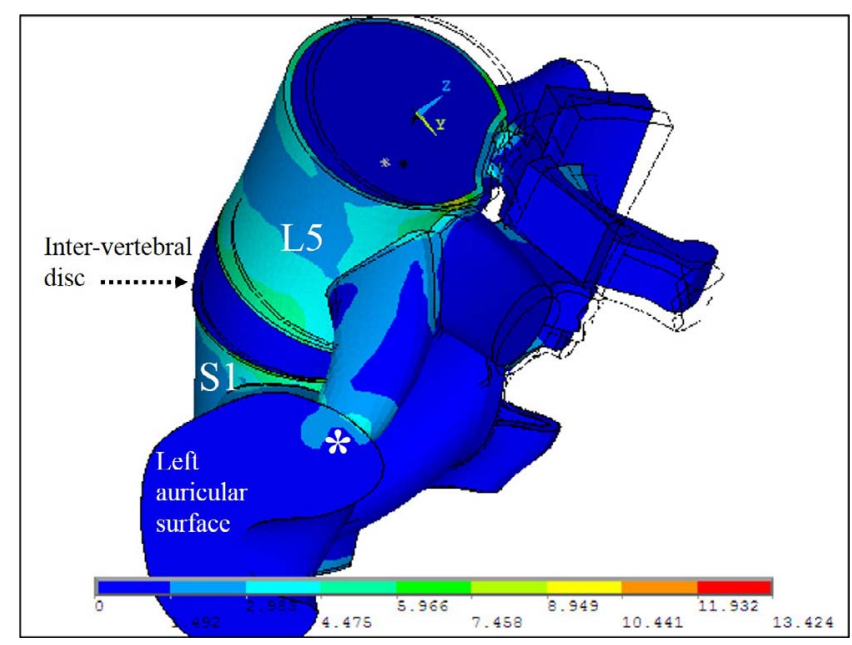

Figure 1. Lumbosacral transitional vertebra model seen from the left-superior aspect. The asterisk marks the L5-S1 accessory articulation of the left side. The left auricular surface and the L5-S1 disc are labeled and moment axes are shown on top of the L5 body.

intervertebral discs. All dimensions were also reviewed and cross-checked from existing literature as well as from dried bones used for this study. ${ }^{10,36}$ The L5-S1 accessory articulation was represented as an extension of the left L5 transverse process forming a diarthrodial joint with the sacral ala.

The models were then transferred from the CATIA software platform to Hypermesh (13.0, Altair Inc., Troy, Michigan) software using IGES files (*.igs format). Finite Element models were then created with nodes and elements assigned appropriate material properties to the model constituents. ${ }^{37,38}$ Finite Element analysis was performed using the ANSYS 12.0 software version. Boundary conditions and loading parameters were applied in accordance to values available from available literature. ${ }^{39}$ The lumbosacral junctions in both the models were subject to simulated flexion, extension, left and right lateral bending, left and right axial rotation using similar parameters of virtual preloading and predetermined moments of force. The outcomes were recorded in terms of ROM (in degrees) at the lumbosacral junction, and stress generated at each lumbosacral articulating surface (including vertebral end-plate contact, facets, L5 pars interarticularis and the anomalous accessory articulation) and at the osseous segment (pars interarticularis) as von Meiss stress measured in MPa units.

\section{RESULTS}

Table 1 and Figure 2 compare the ROM between the two models. Tables 2(a) and (b) and Figures 3 
Table 1. Shows the range of motion (ROM) in degrees, compared between the normal and L5-S1 accessory articulation (AA) models for the same magnitude of loading at the lumbo-sacral junction (preload $=750 \mathrm{~N}$; moment $=1 \mathrm{Nm}$ ).

\begin{tabular}{lcccccc}
\hline & Flexion & Extension & Left Lateral Bending & Right Lateral Bending & Left Axial Rotation & Right Axial Rotation \\
\hline ROM (normal) & 3.05 & 3.02 & 4.34 & 4.33 & 1.32 & 1.40 \\
ROM (AA) & 2.25 & 3.12 & 3.09 & 2.86 & 0.55 & 1.03 \\
\hline
\end{tabular}

and 4 compare loading between the normal and the L5-S1 LSTV junctions. ROM observed at the two lumbosacral models with flexion, extension, left and right lateral bending, left and right axial rotation were different from each other with the same parameters applied to the models to generate a specific motion. Contact forces generated at the vertebral end-plates, facet joints, pars interarticularis, and the L5-S1 accessory articulation demonstrated wide variations between the two models with the same loading conditions and rotational moments applied on them to elicit the specific motion.

ROM (in degrees) and von Meiss stress ( $\mathrm{MPa}$ ) from the LSTV model versus the normal model:

(a) Flexion (sagittal plane): Flexion was restricted, $2.25^{\circ}$ vs. $3.05^{\circ}$ in the normal model. Vertebral end-plate contact stress was greater 9.41 vs. 7.93 ; facet loading increased: leftright $=6.16$ and 4.91 vs. 5.81 and 5.53; pars interarticularis demonstrated lower stress: left-right $=3.73$ and 3.90 vs. 6.59 and 6.34 . The L5-S1 accessory articulation shared a magnitude of $6.30 \mathrm{MPa}$ on the left, during flexion.

(b) Extension (sagittal plane): Extension was increased, 3.12 vs. 3.02 in the normal. Vertebral end-plate contact stress was greater 10.23 vs. 8.60 ; facet loading decreased: left-right $=6.00$ and 4.73 vs. 6.46 and 5.73 ;

ROM comparison between the intact and accessory articulation L5-S1 models

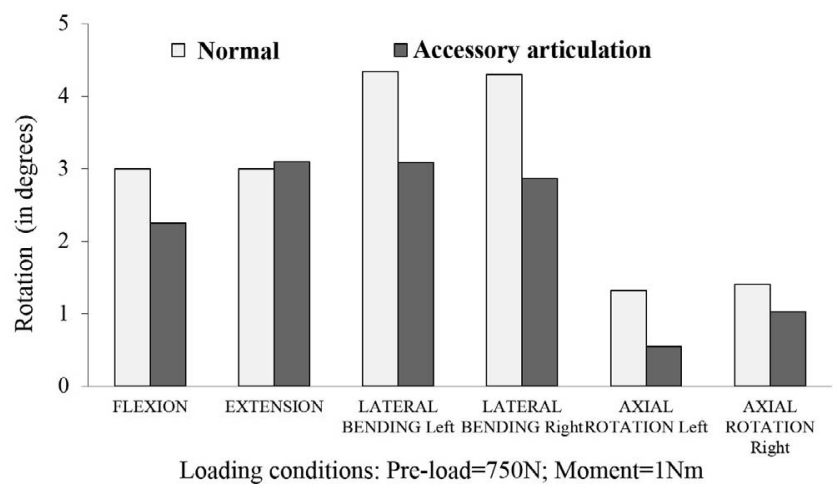

Figure 2. Comparison of range of motion (ROM) between the normal and lumbosacral transitional vertebra (L5-S1 accessory articulation) model shown. pars interarticularis demonstrated lower stress: left-right $=4.93$ and 4.78 vs. 5.90 and 6.10. The LSTV di-arthrosis stress was measured at $6.69 \mathrm{MPa}$, in extension.

(c) Left lateral bending (coronal plane): Left lateral bending was restricted, 4.34 vs. 3.09 in the normal model. Vertebral end-plate contact stress was greater 11.13 vs. 8.11; facet loading was increased: left-right $=6.10$ and 3.94 vs. 3.84 and 4.45; pars interarticularis demonstrated lower stress: left-right $=$ 7.22 and 6.96 vs. 6.18 and 5.86. The LSTV left di-arthrosis stress was measured at 7.44 MPa, with left lateral bending.

(d) Right lateral bending (coronal plane): Right lateral bending was restricted, 2.86 vs. 4.33 in the normal model. Vertebral end-plate contact stress was greater 9.50 vs. 8.12 ; facet loading was decreased: left-right $=3.98$ and 3.14 vs. 3.42 vs. 4.10 ; pars interarticularis demonstrated lower stress: left-right $=4.86$ and 4.98 vs. 6.05 and 5.84. The LSTV left diarthrosis stress was measured at $6.72 \mathrm{MPa}$, with right lateral bending.

(e) Left axial rotation (transverse plane): Left axial rotation was restricted, 0.55 vs. 1.32 in the normal model. Vertebral end-plate contact stress was greater 20.10 vs. 11.78 ; facet loading was decreased: left-right $=3.98$ and 4.65 vs. 5.98 and 5.72; pars interarticularis demonstrated lower stress: left-right $=4.45$ and 4.9 vs. 7.44 and 7.22. The LSTV left diarthrosis stress was measured at $5.18 \mathrm{MPa}$, with left axial rotation.

(f) Right axial rotation (transverse plane): Right axial rotation was restricted, 1.40 vs. 1.03 in the normal model. Vertebral end-plate contact stress was greater 18.17 vs. 11.54; facet loading was decreased: left-right $=3.49$ and 5.71 vs. 4.51 and 3.73 ; pars interarticularis demonstrated marginally lower stress: leftright $=6.28$ and 6.56 vs. 6.86 and 6.58 . The LSTV left di-arthrosis stress was measured at $6.09 \mathrm{MPa}$, with right axial rotation. 
Table 2. (a) Shows the von Meiss stress [MPa] patterns in the L5-S1 articulations and at the pars interarticularis in the normal model. (b) Similar parameters shown in the L5-S1 transitional model. Load at the L5-S1 accessory articulation (AA) is an additional parameter.

\begin{tabular}{|c|c|c|c|c|c|c|}
\hline & Flexion & Extension & Left Lateral Bending & Right Lateral Bending & Left Axial Rotation & Right Axial Rotation \\
\hline \multicolumn{7}{|l|}{ (a) Normal } \\
\hline Vertebral end-plate & 7.93 & 8.60 & 8.11 & 8.12 & 11.78 & 11.54 \\
\hline Left facet joint & 5.81 & 6.46 & 3.84 & 3.42 & 5.98 & 4.51 \\
\hline Right facet joint & 5.53 & 5.73 & 4.45 & 4.10 & 5.72 & 3.73 \\
\hline Left pars interarticularis & 6.59 & 5.90 & 6.18 & 6.05 & 7.44 & 6.86 \\
\hline Right pars interarticularis & 6.34 & 6.10 & 5.86 & 5.84 & 7.22 & 6.58 \\
\hline \multicolumn{7}{|l|}{ (b) $\mathrm{AA}$} \\
\hline Vertebral end-plate & 9.41 & 10.23 & 11.13 & 9.50 & 20.10 & 18.17 \\
\hline Left Facet Joint & 6.16 & 6.00 & 6.10 & 3.98 & 3.98 & 3.49 \\
\hline Right Facet Joint & 4.91 & 4.73 & 3.94 & 3.14 & 4.65 & 5.71 \\
\hline Left Pars interarticularis & 3.73 & 4.93 & 7.22 & 4.86 & 4.45 & 6.28 \\
\hline Right Pars interarticularis & 3.90 & 4.78 & 6.96 & 4.98 & 4.9 & 6.56 \\
\hline${ }^{*} \mathrm{~L} 5-\mathrm{S} 1 \mathrm{AA}$ & 6.30 & 6.69 & 7.44 & 6.72 & 5.18 & 6.09 \\
\hline
\end{tabular}

Overall, the transitional model demonstrated restricted movements at the lumbosacral joints. Also, the LSTV pars interarticularis showed asymmetric (left $>$ right) load distribution. The left facet ipsilateral to the L5-S1 accessory articulation showed lesser loading, probably due to the dimensional variation related to facet tropism seen commonly with LSTV variants and incorporated into our model. ${ }^{7}$

\section{DISCUSSION}

Load-bearing pattern and range of planar motion at the LSTV accessory-articulation is different from normal lumbosacral junctions. More specifically, loading at the vertebral end-plates was found to be elevated during movements in the LSTV model used in the study. Stress at the facet articulation and pars interarticularis were correspondingly elevated in both the models for similar moments, for all excursions at the lumbosacral junction. The accessory articulation between the extended L5 trans-

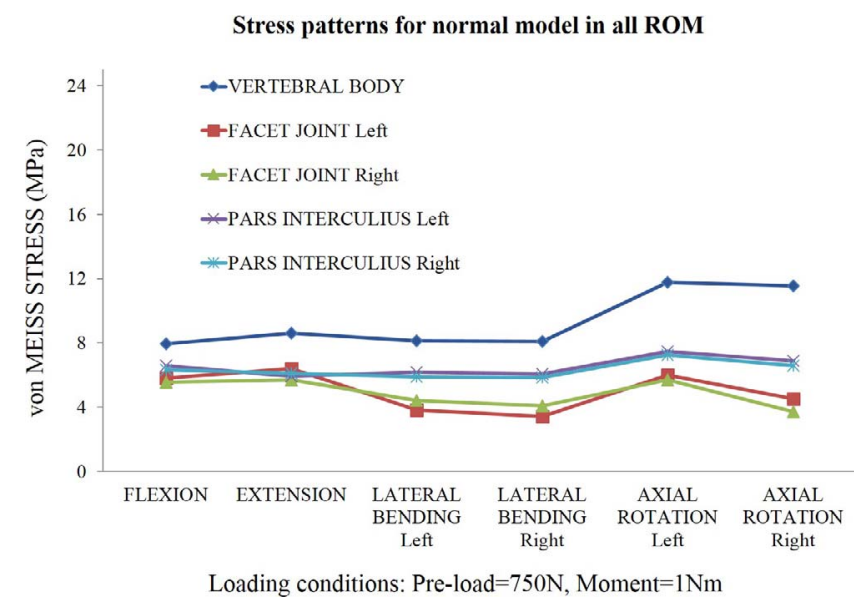

Figure 3. Graphs for the normal lumbosacral junction showing stress patterns at different anatomic locations at the L5-S1 junction with different movements. Abbreviation: ROM, range of motion. verse process and the ala of the sacrum exhibited expected stress patterns based on physiological moments in all three planes of movement.

Lateral bending and axial rotation at the L5-S1 junction elevated stress at the L5-S1 vertebral endplates. Lateral bending in the L5-S1 transitional model showed increased stress at the pars interarticularis and at the accessory articular junction as reported in the literature. These stress patterns restrict the range of lateral bending in comparison to the normal models. Similarly, the range of axial rotation is restricted by the accessory articulation. Any attempt of axial rotation generated higher stress levels at the L5-S1 accessory articulation. Additionally, in the normal model, stress levels in the pars interarticularis during axial rotation were observed to be greater than the transitional variant. This probably resulted due to the arrest of loading at the accessory articulation during the axial rotation that prevented the rotational torque propagating to the pars.

\section{Stress patterns in the L5-S1 accessory articulation model for all ROM}

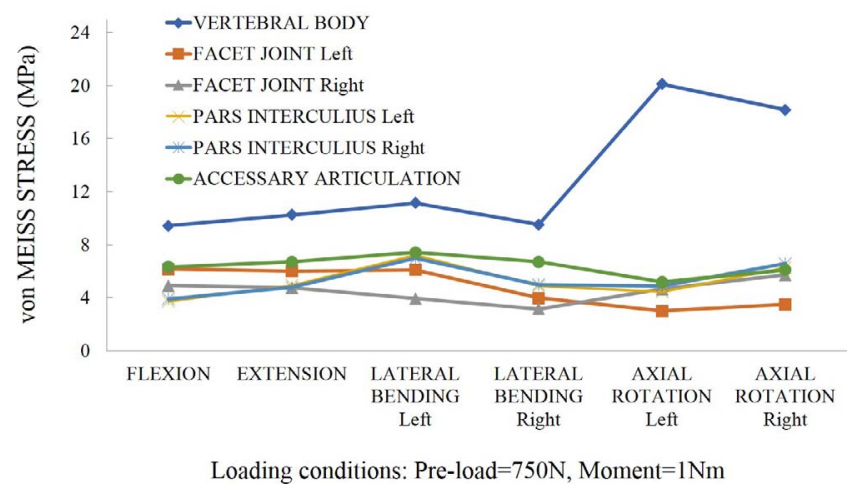

Figure 4. Graphs for the lumbosacral transitional vertebrae (left-sided accessory articulation) model showing stress patterns at different anatomic locations at the L5-S1 junction, with different movements. Abbreviation: ROM, range of motion. 
Analysis of the ROM in the two models shows that the different ranges show dissimilar values of structural loading despite identical stress conditions. Flexion and extension moments in the two models were similar in their ROMs. However, lateral rotation was restricted bi-directionally in the transitional model. This restriction may potentially pose risks for the development of higher stress levels at the LSTV model for a physiological moment that may present with a grossly reduced degree of lateral bending or axial rotation. These observations demonstrate that the lumbosacral junctions with L5-S1 accessory articulation may develop stress levels at the accessory articulation, the facets, the vertebral end-plates, and the pars even with lesser degree of excursions.

Axial rotations in the LSTV model showed that a rotation to the left (ipsilateral to the accessory articulation) is restricted more than the other side. Other parameters of stress in the transitional model were substantially elevated with this rotation. The vertebral end-plate stress, facet, and pars loading in the transitional model were in general higher than the normal model. The accessory L5-S1 articulation connecting the extended L5 transverse process with the sacral ala restricted axial rotation in the transverse plane. The torque generated with this rotation may result in increased stress at the site of the accessory articulation. This "strut-like" diarthrodial articulation at the lumbosacral junction may limit the force of the rotation (around a vertical, instantaneous axis of rotation near the nucleus pulposus). Clinical and radiological isotope uptake studies have shown pain, inflammation, and higher stress levels in patients with LBP due to accessory LSTV articulations. The lower facet and pars loading (as observed in this study) may indicate that the stress generated with axial torque in this LSTV variant may have been routed through the accessory L5-S1 articulation and not propagated to the neural arch elements.

FEM studies involving LSTV anomalies are rarely found in the literature. This pilot study demonstrates distinct loading patterns at these LSTV lumbosacral junctions affecting stressors for the vertebral endplates, the facets, pars interarticularis, and the accessory articulation site, with physiological loading. Further information on the excursion ranges and the loading magnitudes at these anomalous junctions with simulations may help clinical decision-making on the impact of excision of impinging accessory L5 transverse process, assessing the risk of destabilizing the joint with extended surgical instrumentation at the junction, or in deciding appropriate intervention to treat stiffness and pain at the lower back. This is to help safe and effective clinical decision-making involving transitional anomalies. Though the initial findings of this pilot project is encouraging, there are a few limitations of this study. The number of iterations performed and the number of models used in this study are not adequate for evaluating of statistical significance of the outcomes. This could be tested in the future with the availability of other LSTV models in the future. This study was undertaken as a step towards the direction creating function finite element modeling (FEM) LSTV models and to compare loading simulation outcomes with a normal variant.

\section{CONCLUSIONS}

This pilot study attempts to model the ROM and loading patterns in a common LSTV variant and offers a mechanistic explanation for symptomatic LSTV pathology. Given a diverse range of clinical presentation and the great variability in the anatomical pain-source in such anomalies, it is beyond the scope of this study to recommend any specific treatment approaches in light of the findings enumerated above. However, our study detects differences in ROM and loading patterns in the specific LSTV model investigated here. Larger studies with different LSTV models may help better delineate and compare movement and loading patterns at the lumbosacral and sacroiliac junctions associated with the entire spectrum LSTV variants.

\section{ACKNOWLEDGMENTS}

All the authors acknowledge the logistical and technical support provided by the Department of Anatomy, SRM Medical College and the School of Mechanical Engineering, SRM Institute of Science and Technology toward carrying out this study. Special thanks to Dr. D Kingsly Jeba Singh, Professor and Head, School of Mechanical Engineering, SRM Institute of Science and Technology, Tamil Nadu, India for his encouragement and help with logistic support and facilitating the experiments.

\section{REFERENCES}

1. Bron JL, van Royen BJ, Wuisman PI. The clinical significance of lumbosacral transitional anomalies. Acta Orthop Belg. 2007;73(6):687-695. 
2. Castellvi AE, Goldstein LA, Chan DP. Lumbosacral transitional vertebrae and their relationship with lumbar extradural defects. Spine (Phila Pa 1976). 1984;9(5):493-495.

3. Hsieh CY, Vanderford JD, Moreau SR, Prong T. Lumbosacral transitional segments: classification, prevalence, and effect on disk height. $J$ Manipulative Physiol Ther. 2000;23(7):483-489.

4. Jancuska JM, Spivak JM, Bendo JA. A review of symptomatic lumbosacral transitional vertebrae: Bertolotti's syndrome. Int J Spine Surg. 2015;9:42.

5. Mahato NK. Implications of structural variations in the human sacrum: why is an anatomical classification crucial? Surg Radiol Anat. 2016;38(8):947-954.

6. Vergauwen S, Parizel PM, van Breusegem L, et al. Distribution and incidence of degenerative spine changes in patients with a lumbo-sacral transitional vertebra. Eur Spine $J$. 1997;6(3):168-172.

7. Mahato NK. Facet dimensions, orientation, and symmetry at L5-S1 junction in lumbosacral transitional states. Spine (Phila Pa 1976). 2011;36(9):E569-E573.

8. Elster AD. Bertolotti's syndrome revisited. Transitional vertebrae of the lumbar spine. Spine (Phila Pa 1976). 1989;14(12):1373-1377.

9. Pekindil G, Pekindil Y, Sarikaya A. Degenerative lumbosacral transitional articulation: atypical increased sacral uptake on planar bone scintigraphy. Clin Nucl Med. 2002;27(11):840-841.

10. Mahato NK. Morphometric analysis and identification of characteristic features in sacra bearing accessory articulations with L5 vertebrae. Spine J. 2010;10(7):616-621.

11. White AA 3rd, Panjabi MM. The basic kinematics of the human spine. A review of past and current knowledge. Spine (Phila Pa 1976). 1978;3(1):12-20.

12. Panjabi MM. A hypothesis of chronic back pain: ligament subfailure injuries lead to muscle control dysfunction. Eur Spine J. 2006;15(5):668-676.

13. Panjabi MM. Clinical spinal instability and low back pain. J Electromyogr Kinesiol. 2003;13(4):371-379.

14. Adams MA. Biomechanics of back pain. Acupunct Med. 2004;22(4):178-188.

15. Adams MA, Hutton WC. The effect of posture on the role of the apophysial joints in resisting intervertebral compressive forces. J Bone Joint Surg. 1980;62(3):358-362.

16. Willigenburg NW, Kingma I, Hoozemans MJ, van Dieen JH. Precision control of trunk movement in low back pain patients. Hum Mov Sci. 2013;32(1):228-239.

17. Weiler PJ, King GJ, Gertzbein SD. Analysis of sagittal plane instability of the lumbar spine in vivo. Spine (Phila $\mathrm{Pa}$ 1976). 1990;15(12):1300-1306.

18. Ogston NG, King GJ, Gertzbein SD, Tile M, Kapasouri A, Rubenstein JD. Centrode patterns in the lumbar spine. Baseline studies in normal subjects. Spine (Phila Pa 1976). 1986;11(6):591-595.

19. Kirkaldy-Willis WH, Farfan HF. Instability of the lumbar spine. Clin Orthop Relat Res. 1982(165):110-123.

20. Beazell JR, Mullins M, Grindstaff TL. Lumbar instability: an evolving and challenging concept. J Man Manip Ther. 2010;18(1):9-14.

21. Izzo R, Guarnieri G, Guglielmi G, Muto M. Biomechanics of the spine. Part II: spinal instability. Eur $J$ Radiol. 2013;82(1):127-138.
22. Ebenbichler GR, Leitgeb J, Amtmann G, et al Degeneration and instability and the relation to patients' function late after lumbar disc surgery: data from a 12-year follow-up. Am J Phys Med Rehab. 2016;95(12):871-879.

23. Vanti C, Conti C, Faresin F, Ferrari S, Piccarreta R. The relationship between clinical instability and endurance tests, pain, and disability in nonspecific low back pain. $J$ Manipulative Physiol Ther. 2016;39(5):359-368.

24. Brumagne S, Janssens L, Janssens E, Goddyn L. Altered postural control in anticipation of postural instability in persons with recurrent low back pain. Gait Posture. 2008;28(4):657-662.

25. Iguchi T, Ozaki $\mathrm{T}$, Chin $\mathrm{T}$, et al. Intimate relationship between instability and degenerative signs at L4/5 segment examined by flexion-extension radiography. Eur Spine $J$. 2011;20(8):1349-1354.

26. Javadian Y, Behtash H, Akbari M, Taghipour-Darzi M, Zekavat $\mathrm{H}$. The effects of stabilizing exercises on pain and disability of patients with lumbar segmental instability. $J$ Back Musculoskelet Rehabil. 2012;25(3):149-155.

27. Yilmaz B, Yasar E, Taskaynatan MA, et al. Relationship between lumbar muscle strength and proprioception after fatigue in men with chronic low back pain. Turk $J$ Rheumatol. 2010;25(2):68-71.

28. Taskaynatan MA, Izci Y, Ozgul A, Hazneci B, Dursun $\mathrm{H}$, Kalyon TA. Clinical significance of congenital lumbosacral malformations in young male population with prolonged low back pain. Spine (Phila Pa 1976). 2005;30(8):E210-E213.

29. Aihara T, Takahashi K, Ogasawara A, Itadera E, Ono $\mathrm{Y}$, Moriya $\mathrm{H}$. Intervertebral disc degeneration associated with lumbosacral transitional vertebrae: a clinical and anatomical study. J Bone Joint Surg. 2005;87(5):687-691.

30. Luoma K, Vehmas T, Kerttula L, Gronblad M, Rinne E. Chronic low back pain in relation to modic changes, bony endplate lesions, and disc degeneration in a prospective MRI study. Eur Spine J. 2016;25(9):2873-2881.

31. Luoma K, Vehmas T, Raininko R, Luukkonen R, Riihimaki H. Lumbosacral transitional vertebra: relation to disc degeneration and low back pain. Spine (Phila Pa 1976). 2004;29(2):200-205.

32. Panjabi MM, Oxland TR, Yamamoto I, Crisco JJ. Mechanical behavior of the human lumbar and lumbosacral spine as shown by three-dimensional load-displacement curves. J Bone Joint Surg. 1994;76(3):413-424.

33. Mahato NK. Complexity of neutral zones, lumbar stability and subsystem adaptations: probable alterations in lumbosacral transitional vertebrae (LSTV) subtypes. Med Hypotheses. 2013;80(1):61-64.

34. Kanemura A, Doita M, Kasahara K, Sumi M, Kurosaka M, Iguchi T. The influence of sagittal instability factors on clinical lumbar spinal symptoms. J Spinal Disord Tech. 2009;22(7):479-485.

35. Abbott JH, McCane B, Herbison P, Moginie G, Chapple C, Hogarty T. Lumbar segmental instability: a criterion-related validity study of manual therapy assessment. BMC Musculoskelet Disord. 2005;6:56.

36. Mahato NK. Variable positions of the sacral auricular surface: classification and importance. Neurosurg Focus. 2010;28(3):E12.

37. Chen SH, Zhong ZC, Chen CS, Chen WJ, Hung C. Biomechanical comparison between lumbar disc arthroplasty and fusion. Med Eng Phys. 2009;31(2):244-253. 
38. Li H, Wang Z. Intervertebral disc biomechanical analysis using the finite element modeling based on medical images. Comput Med Imaging Graph. 2006;30(6-7):363-370.

39. Denoziere G, Ku DN. Biomechanical comparison between fusion of two vertebrae and implantation of an artificial intervertebral disc. J Biomech. 2006;39(4):766-775.

Disclosures and COI: The authors received no funding for this study and report no conflicts of interest.

Corresponding Author: Niladri Kumar Mahato, MBBS, MS, DNB, PhD, Senior-Lecturer,
Department of Preclinical Sciences, Faculty of Medical Sciences, The University of The West Indies, St. Augustine, Trinidad and Tobago. Phone: (868) 372-6894; Fax: (868) 662-9148; Email: niladri. mahato@sta.uwi.edu.

Published 22 February 2019

This manuscript is generously published free of charge by ISASS, the International Society for the Advancement of Spine Surgery. Copyright (C) 2019 ISASS. To see more or order reprints or permissions, see http://ijssurgery.com. 